\title{
Adapting the Unified Theory of Acceptance and Use of Technology (UTAUT) as a Tool for Validating User Needs on the Implementation of e-Trial Software Systems
}

\author{
Amani J. Algharibi \\ Theodoros N. Arvanitis \\ Biomedical Informatics, Signals and Systems Research Lab. \\ School of Electronic, Electrical and Computer Engineering \\ The University of Birmingham, Edgbaston, B15 2TT \\ axa936@bham.ac.uk \\ t.arvanitis@bham.ac.uk
}

\begin{abstract}
This paper presents an adapted version of the Unified Theory of Acceptance and Use of Technology Model to be utilised as a validation tool of captured user needs and requirements of particular interactive software technologies, within the framework of Clinical Trial Management Systems (CTMS). In particular, this model is used to assess the users' acceptance and technology adoption of specific CTMS modules of the electronic Primary Care Research Network (ePCRN) Clinical Trial Management Framework System. We present modifications on the variable of the key constructs of UTAUT, while we introduce our own moderating factors for the model in the context of validating an eligibility criteria tool for primary care and community-based clinical research.
\end{abstract}

Health Information Technology (IT); Technology Acceptance Model (TAM); and the Unified Theory of Acceptance and Use of Technology Theory (UTAUT)

\section{INTRODUCTION}

The capturing of user needs, during the processes of design and implementation of novel interactive systems, presents some interesting and complex socio-technical challenges. On the one hand, indirect capture of user needs through traditional elicitation methods such as: task analysis might fail to effectively account for all significant factors that relate to the intended context of use of the proposed technology (Norman, 2002). On the other hand, a direct elicitation of requirements from actual users might not consider the potential of future adoption of interactive technologies within a specific context; because users might not be able to envision future tasks, organizational perspectives and technologies that are different from what they are mostly familiar (Swanson, 1988)

Davis and collaborators (1989) have argued that in order to make informed design decisions on future technological solutions and achieve the full potential of information systems, it is important to comprehend the key factors of user adoption and intention of use within a particular domain and organizational context. His proposed model of Technology Acceptance (TAM) has looked into factors of usability and perceived usefulness in order to study users' individual variability in their future intention to use and adopt technology ( $F$ D Davis, 1986) and (Fred D. Davis, 1989). As such, TAM could help designers to evaluate and assess the appropriateness of particular technological solutions. Since its original inception, Davis' model has been tested and applied by numerous researchers on various system types and within the context of many domains (Lee, 2003). This popularity resulted on gradual improvements to the theory, and the most comprehensive version of this model today is: the Unified Theory of Acceptance and Use of Technology (UTAUT) (Venkatesh, Morris, Gordon, \& Davis, 2003)

In this paper, we are proposing to adapt UTAUT to be utilised as a validation tool of captured user needs and requirements of particular interactive software technologies, within the framework of Clinical Trial Management Systems (CTMS). CTMS 
are information management systems that support the design, implementation, data capturing and analysis of clinical research studies such as: Randomised Control Trials (RCT) (Shortliffe, 2006). In particular, the work is looking into validating the user acceptance and adoption of specific CTMS modules of the electronic Primary Care Research Network (ePCRN) which is a Clinical Trial Management Framework System (Peterson, Fontaine, \& Speedie, 2006), (Sim \& Weissman, 2007) and (ePCRN, 2006). We aim to further explore and modify the key constructs and moderating factors of the UTAUT to support the validation of an eligibility criteria tool for primary care and community-based clinical research.

\section{USER ACCEPTANCE AND E-HEALTH SYSTEMS}

In this section, we summarise the important features of TAM, TAM 2, and UTAUT as the most commonly used models of user acceptance within the current information systems literature. We then briefly discuss technology acceptance as an emerging validation tool in health-related information systems. TAM initially originated from the Theory of Reasoned Action (TRA); a theory that is used in social psychology to explain a wide range of behaviours (Sheppard, Hartwick, \& Warshaw, 1988). However, TAM is particularly used within the information systems domain, and is mainly concerned with endusers' intentions and ways to influence those for an increased technology acceptance and use (Davis, 1986). Its key constructs are: Perceived Usefulness (PU) and Perceived Ease of Use (PEOU). On the basis of these two constructs and by combining another key construct that is users' attitude (ATT) towards information technology (IT), TAM aims to predict users' behavioural intention of use of technologies. TAM 2 and updated versions of TAM has Subjective Norm (SN) as an additional key construct instead of the Attitude (ATT) component (Venkatesh \& Davis, 2000). Recently, UTAUT provides a more extended and unified model of user acceptance (Venkatesh, et al., 2003) - see figure 1. UTAUT is more comprehensive as it encompasses eight former research models of IT usage behaviour. UTAUT renames the old key constructs in the following way: PU has become Performance Expectancy, PEOU has become Effort Expectancy, and SN has become Social Influence. The UTAUT also has a Facilitating Conditions construct to predict Behavioural Intention.

The results of user acceptance as a model of validation have been very promising; early use of it i.e. during the process of systems development, accounts for $70 \%$ of the variance in usage intention, and about $50 \%$ in actual use (Venkatesh, et al., 2003). Particularly, in a recent study Holden and Karsh concluded that "an important future direction for TAM is to adapt the model specifically to the healthcare context, using beliefs elicitation methods." (Holden \& Karsh, 2010),

\section{UTAUT IN THE CONTEXT OF E-TRIALS}

The ePCRN Eligibility Criteria tool (Arvanits et al., 2007) is a module for capturing clinical trials' eligibility criteria as part of the ePCRN System (ePCRN, 2006). It provides a dynamic and flexible knowledge-driven graphical interface for querying electronic Healthcare Records (eHRs). This interface supports the identification of clinical concepts such as: clinical problems and lab tests. It provides the end-user with dynamic panes of six generic concepts including: age, gender, clinical problems, laboratory tests, vital signs, and drugs. Some more specific concepts come under each of the generic ones. At the detailed level, end-users can dynamically add or remove concepts by applying whatever rules they wish to; and can logically combine them with other concepts for specific studies. The main technological objective of the tool was to achieve the networked-enabled eligibility criteria capture of clinical trials' in a standard, efficient and intuitive way. This is important in order to support researchers in their identification and recruitment of potential subjects for RCT studies. The adapted UTAUT will be used for the validation of this tool with clinical researchers as the users of the technology.

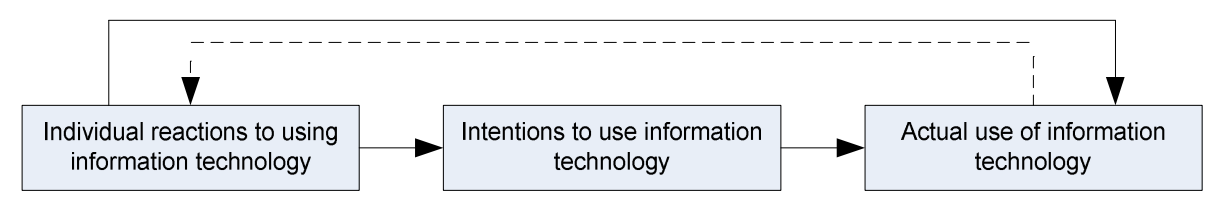

Figure 1: Basic Concept Underlying User Acceptance Models (Venkatesh et al.) 
Adapting the Unified Theory of Acceptance and Use of Technology (UTAUT) as a Tool for Validating User Needs on the Implementation of e-Trial Software Systems

Amani J. Algharibi and Theodoros N. Arvanitis

\section{PROPOSED ADAPTATION OF THE UTAUT}

There are two main additions to the Proposed UTAUT Model. Firstly, condensing (age, gender, experience level, speciality, and voluntariness to use the system) under one dimension called Individual
Factors. Secondly, the introduction of Technology Anxiety and Adaption Timeline as new dimensions along with relevant variables. Figure 2 illustrates the Proposed UTAUT Model:

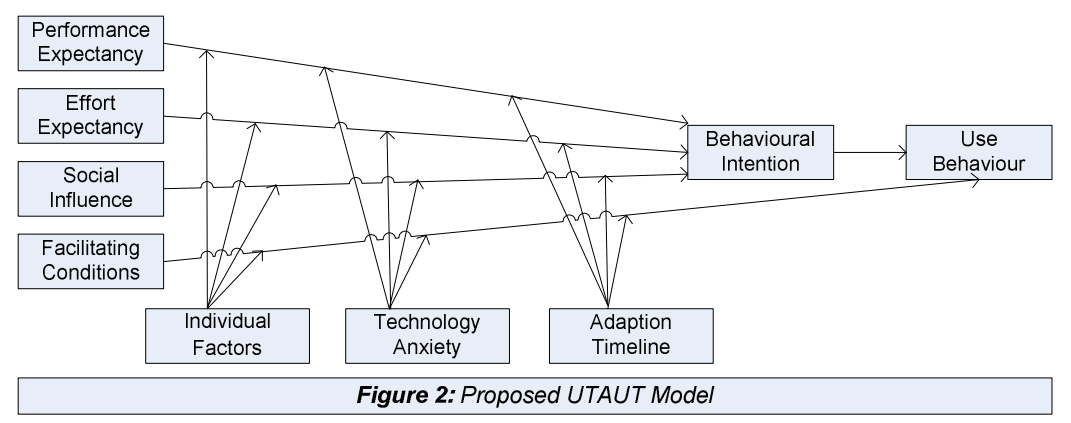

Table 1 shows the proposed improved dimension of individual factors and introduces the dimensions of
Technology Anxiety and Adaptation Timeline. It also includes specific variables for the ePCRN study.

Table1: Variables of Moderators

\begin{tabular}{|l|l|l|}
\hline Moderators & Explanation & Variables \\
\hline $\begin{array}{l}\text { Individual } \\
\text { Factors }\end{array}$ & $\begin{array}{l}\text { This dimension condensed the four old moderators } \\
\text { (age, gender, experience level, and voluntariness to } \\
\text { use the system) under one dimension. It also added } \\
\text { (speciality) to see if it would make any difference. }\end{array}$ & $\begin{array}{l}\text { Age, gender, experience level, speciality, and } \\
\text { voluntariness to use the system }\end{array}$ \\
\hline $\begin{array}{l}\text { Technology } \\
\text { Anxiety }\end{array}$ & $\begin{array}{l}\text { This is a newly proposed dimension. It is supposed } \\
\text { to obtain information about an individual's } \\
\text { psychological and/or habitual readiness to adapt } \\
\text { change. }\end{array}$ & $\begin{array}{l}\text { Openness for a dramatic change in work habits if } \\
\text { necessary; likelihood to become technology- } \\
\text { oriented due to the nature of the field; prior } \\
\text { knowledge of the need to use health IT; heritage of } \\
\text { experience to facilitate putting this system to use; } \\
\text { and possibility of being more comfortable if trained } \\
\text { in advanced }\end{array}$ \\
\hline $\begin{array}{l}\text { Adaption } \\
\text { Timeline }\end{array}$ & $\begin{array}{l}\text { This is another newly proposed dimension. It is } \\
\text { supposed to obtain information about the } \\
\text { importance of allowing enough time for an individual } \\
\text { to completely absorb change. }\end{array}$ & $\begin{array}{l}\text { Adequate time to learn or get trained; sufficient } \\
\text { information or training during this time; enough time } \\
\text { to get used to and master the system; ability to } \\
\text { improve the quality of work I do after this time } \\
\text { elapsed; and level of confidence to carry out clinical } \\
\text { trials by the help of the system after this time }\end{array}$ \\
\hline
\end{tabular}


Table 2 shows the key constructs as well as their e-trial specific variables, those which are appropriate for the validation effort of ePCRN.

Table2: Variables of Key Constructs

\begin{tabular}{|c|c|c|}
\hline Key Constructs & Definitions (Holden \& Karsh, 2010) & Variables \\
\hline $\begin{array}{l}\text { Performance } \\
\text { Expectancy }\end{array}$ & $\begin{array}{l}\text { An individual's perception that using an IT system } \\
\text { will enhance job performance }\end{array}$ & $\begin{array}{l}\text { System's effectiveness, system's improvement of } \\
\text { work performance, system's improvement of } \\
\text { productivity, chance to gain transferable skills, } \\
\text { and better control of work }\end{array}$ \\
\hline $\begin{array}{l}\text { Effort } \\
\text { Expectancy }\end{array}$ & $\begin{array}{l}\text { An individual's perception that using an IT system } \\
\text { will be free of effort }\end{array}$ & $\begin{array}{l}\text { Easiness of accessing data, clarity of data, ability } \\
\text { to identify relevant data, smoothness of } \\
\text { interacting with the system, and system's overall } \\
\text { presentation and outline }\end{array}$ \\
\hline Social Influence & $\begin{array}{l}\text { An individual's perception of the degree to which } \\
\text { important other people approve or disapprove of } \\
\text { the target behaviour }\end{array}$ & $\begin{array}{l}\text { Organisational encouragement; organizational } \\
\text { pressure for change; management } \\
\text { communication and involvement in the change } \\
\text { process; experience of a demo beforehand; and } \\
\text { availability of an "open door" policy to discuss } \\
\text { aspects related to change }\end{array}$ \\
\hline $\begin{array}{l}\text { Facilitating } \\
\text { Conditions }\end{array}$ & $\begin{array}{l}\text { An individual's perception of how easy or difficult } \\
\text { it will be to perform the target behaviour (self- } \\
\text { efficacy), of factors that impede or facilitate the } \\
\text { behaviour (facilitating conditions), or of the } \\
\text { amount of control that one has over performing } \\
\text { the behaviour (controllability) }\end{array}$ & $\begin{array}{l}\text { Comprehensiveness of manual or training } \\
\text { session; ability to imagine applying the system to } \\
\text { conducts tasks; mention of the extensiveness of } \\
\text { search criteria; offer of steps that are logical to } \\
\text { use, apply, and recall; and cover of all essentials } \\
\text { to perform tasks and overcome difficulty }\end{array}$ \\
\hline
\end{tabular}

\section{FUTURE WORK}

The next step of our research will construct a specific questionnaire instrument that implements the above key constructs and modified factors. A pilot study will be conducted and if necessary, adjustments will be made to the proposed Model accordingly. Following this, the model will be applied within the context of ePCRN Eligibility Criteria tool usage and as a part of a Primary Care RCT Trial

\section{REFERENCES}

Arvanitis, T.N., Taweel, A., Zhao, L., Delaney, B.C., Peterson, P.K., Speedie, S.M., Sim, I., Weissman, J., Fontaine, P., Lange, C., Janowiec, M., \& Stone, J. (2007). Supporting E-Trials Over Distributed Networks: a tool for capturing randomised control trials (RCT) eligibility criteria using the National Cancer Institute's (NCl) Enterprise Vocabulary Services (EVS). Technology and Health Care, 15(5), 298-299.

Davis, F. D. (1986). A Technology Acceptance Model for Empirically Testing New End-User Information Systems: Theory and Results Doctoral dissertation Massachusetts Institute of Technology Davis, F. D. (1989). Perceived Usefulness, Perceived Ease of Use, and User Acceptance of Information Technology. MIS Quarterly, 13(3), 319340.

ePCRN. (2006). electronic Primary Care Research Network, from http://www.epcrn.bham.ac.uk/ Field, A. H., Graham. (2003). How to Design and Report Experiments London: SAGE Ltd.
Holden, R. J., \& Karsh, B.-T. (2010). The Technology Acceptance Model: Its past and its future in health care. Journal of Biomedical Informatics, 43(1), 159-172.

Lee, Y. K., Kenneth A. Larsen, Kai R. T. (2003). The Technology Acceptance Model: Past, Present and Future. Communications of the Association for Information Systems, 12, 752-780.

Norman, D. (2002). Emotion \& design: Attractive things work better. interactions, 9(4), 36-42. doi: $10.1145 / 543434.543435$

Peterson, K. A., Fontaine, P., \& Speedie, S. (2006). The Electronic Primary Care Research Network (ePCRN): A New Era in Practice-based Research. J Am Board Fam Med, 19(1), 93-97.

Sheppard, B. H., Hartwick, J., \& Warshaw, P. R. (1988). The Theory of Reasoned Action: A MetaAnalysis of Past Research with Recommendations for Modifications and Future Research. Journal of Consumer Research, 15(3), 325.

Shortliffe, E. H. (2006). Biomedical Informatics: Computer Applications in Health Care and Biomedicine (3rd ed.).

Sim, I., Peterson K. A., Speedie, S. M., Fontaine P. L., \& Weissman, J., Delaney B., Arvanitis, T. N., Taweel, A., Zhao, L, Lange, C. Janowiec, M., Stone, J., \& Wolff, A. (2007). The Electronic Primary Care Research Network: A Grid-Based Computing Infrastructure for Community-Based Clinical Trials in Primary Care. Journal of General Internal Medicine 22(59).

Swanson, E. B. (1988). Information System Implementation: Bridging the Gap between Design and Utilization. Homewood IL Irwin

Venkatesh, V., \& Davis, F. D. (2000). A Theoretical Extension of the Technology Acceptance Model: 
Adapting the Unified Theory of Acceptance and Use of Technology (UTAUT) as a Tool for Validating User Needs on the Implementation of e-Trial Software Systems

Amani J. Algharibi and Theodoros N. Arvanitis

Four Longitudinal Field Studies. Management Science, 46(2), 186-204.

Venkatesh, V., Morris, M. G., Gordon, B. D., \& Davis, F. D. (2003). User Acceptance of Information Technology: Toward a Unified View. MIS Quarterly, 27(3), 425-478. 